\title{
Proton NMR Studies of Co(II) Complexes of the Peptide Antibiotic Bacitracin and Analogues: Insight into Structure-Activity Relationship
}

\author{
Jon D. Epperson and Li-June Ming* \\ Department of Chemistry and Institute for Biomolecular Science, University of South Florida, Tampa, Florida 33620-5250
}

Received August 25, 1999; Revised Manuscript Received January 31, 2000

\begin{abstract}
Bacitracin is a widely used metal-dependent peptide antibiotic produced by Bacillus subtilis and Bacillus licheniformis with a potent bactericidal activity directed primarily against Gram-positive organisms. This antibiotic requires a divalent metal ion such as $\mathrm{Zn}$ (II) for its biological activity, and has been reported to bind several other transition metal ions, including $\mathrm{Co}(\mathrm{II}), \mathrm{Ni}$ (II), and $\mathrm{Cu}$ (II). Despite the wide use of bacitracin, a structure-activity relationship for this drug has not been established, and the structure of its metal complexes has not been fully determined. We report here one- and two-dimensional nuclear magnetic resonance (NMR) studies of the structure of the metal complexes of several bacitracin analogues by the use of paramagnetic $\mathrm{Co}$ (II) as a probe. The Co(II) complex of this antibiotic exhibits many well-resolved isotropically shifted ${ }^{1} \mathrm{H}$ NMR signals in a large spectral window ( $\left.200 \mathrm{ppm}\right)$ due to protons near the metal, resulting from both contact and dipolar shift mechanisms. The assignment of the isotropically shifted ${ }^{1} \mathrm{H}$ NMR features concludes that bacitracin $\mathrm{A}_{1}$, the most potent component of the bacitracin mixture, binds to $\mathrm{Co}(\mathrm{II})$ via the His-10 imidazole ring $\mathrm{N}_{\epsilon}$, the thiazoline nitrogen, and the monodentate Glu-4 carboxylate to form a labile complex in aqueous solutions. The free amine of Ile-1 does not bind Co(II). Several different analogues of bacitracin have also been isolated or prepared, and the studies of their $\mathrm{Co}$ (II) binding properties further indicate that the antimicrobial activity of these derivatives correlates directly to their metal binding mode. For example, the isotropically shifted ${ }^{1} \mathrm{H}$ NMR spectral features of the high-potent bacitracin analogues, including bacitracins $A_{1}, B_{1}$, and $B_{2}$, are virtually identical. However, Glu-4 and/or the thiazoline ring does not bind $\mathrm{Co}(\mathrm{II})$ in the bacitracin analogues with low antibiotic activities, including bacitracins $\mathrm{A}_{2}$ and $\mathrm{F}$.
\end{abstract}

Modern drug development relies on the chemical characterization of both biologically active "lead" compounds and their structurally related analogues (1). For example, an analysis of the antibacterial agent sulfanilamide and derivatives led to the discovery of the sulfa drug's pharmacophore and the chemical substituents associated with the activity and potency of the drugs (2). However, drugs that require metal ions for their biological activity cannot be analyzed in this way owing to structural changes upon metal ion binding. For example, a $\sim 180^{\circ}$ twist of the $\mathrm{C} 2-\mathrm{C} 2^{\prime}$ bond in the crystal structure of the antibiotic streptonigrin occurs in the presence of $\mathrm{Fe}$ (II) or $\mathrm{Co}$ (II) (3). To create a meaningful structure-activity relationship for these metal-dependent drugs, the structure must be determined in the presence of the metal ion.

Bacitracin is a metal-dependent peptide antibiotic from cultures of Bacillus subtilis and B. licheniformis, directed primarily against Gram-positive bacteria (4). It is commercially produced in large quantities worldwide as a feed additive for livestock (5) and in human medicinal ointments such as Neosporin and Polysporin (6). It is produced as a mixture of many closely related analogues in which bacitracin $\mathrm{A}_{1}$ is the major component with the highest activity (7). Bacitracin $A_{1}$ contains a thiazoline ring formed by the condensation of the Ile- 1 carboxylate with the $-\mathrm{NH}_{2}$ and

* Correspondence should be addressed to this author. Telephone: (813) 974-2220, Fax: (813) 974-1733, E-mail: ming@ @huma.cas.usf.edu.
- $\mathrm{SH}$ groups of Cys-2, a cyclic heptapeptide structure formed via an amide linkage between the Lys- 6 side chain and the C-terminus, and four D-amino acids (Figure 1A). These unusual structural features may protect this peptide from degradation by proteases $(8)$.

Bacitracin requires a divalent metal ion like $\mathrm{Zn}$ (II) for its potent antimicrobial activity (9) and can form a 1:1 complex with other divalent metal ions, including $\mathrm{Co}$ (II), $\mathrm{Ni}$ (II), and $\mathrm{Cu}$ (II) (10). An early NMR study of $\mathrm{Zn}(\mathrm{II})$ - bacitracin suggested that His-10 and the thiazoline ring sulfur were coordinated to the metal (11). A later electron paramagnetic resonance (EPR) study on $\mathrm{Cu}(\mathrm{II})$-bacitracin suggested that the thiazoline ring nitrogen, the His-10 imidazole, and the carboxylate of Glu-4 and Asp-11 were the ligands (10b). The results from a recent extended X-ray absorption fine structure (EXAFS) study of Zn(II)-bacitracin in the solid form suggested a tetrahedral-like geometry with the thiazoline nitrogen, His-10 imidazole, Glu-4, and the N-terminal amino group as ligands (12), corroborating some previous observations. However, a conclusive metal binding mode was not drawn from these studies, and the structure of metalbacitracin complexes could not be determined from these studies. For example, the tetrahedral geometry in solid may not retain in solution, the ligand Glu-4 cannot be conclusively assigned, the binding status of His-10 (through $\mathrm{N}_{\epsilon}$ or $\mathrm{N}_{\delta}$ ) and the amino group (bound or not) cannot be concluded, the moieties involved in pyrophosphate binding cannot be 


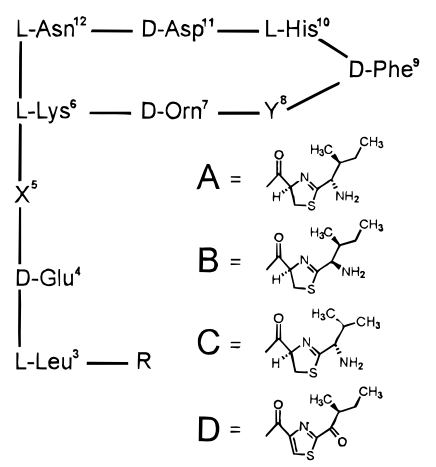

FIGURE 1: Schematic structures of bacitracin analogues: (A) bacitracin $A_{1}$ which has an amino thiazoline ring formed by the condensation of L-Ile-1 with L-Cys-2; (B) bacitracin $\mathrm{A}_{2}$ with a D-allo-Ile-1; (C) bacitracin $\mathrm{B}_{1}$; and (D) bacitracin $\mathrm{F}$ which has a keto thiazole ring. Bacitracins $B_{2}$ and $B_{3}$ have the same structure as bacitracin $A_{1}$ with the exception of a Val substituted for an Ile at positions 5 and 8, respectively. Bacitracin $\mathrm{C}$ has the same structure as $\mathrm{A}_{1}$ with two Val's substituted for the two Ile's at residues 5 and 8 .

identified, and the configuration of the groups other than the coordinated ligands cannot be revealed.

The metal(II)-bacitracin complex was found to bind tightly to $\mathrm{C}_{55}$-isoprenyl pyrophosphate $\left(K_{\mathrm{f}}=1.05 \times 10^{6} \mathrm{M}^{-1}\right)$ (13), which presumably prevents the lipid pyrophosphate from being dephosphorylated by a membrane pyrophosphatase. Since the monophosphate form of the lipid is required to bind UDP-sugars for transport during cell wall synthesis (14), the binding of metal-bacitracin to the lipid pyrophosphate thus inhibits $\mathrm{N}$-glycosylation of nascent proteins in the lumen of the endoplasmic reticulum which serves as the key step in the inhibition of cell wall synthesis by bacitracin. Although a $\mathrm{Co}(\mathrm{II})$ - bacitracin-pyrophosphate ternary complex has been proposed (15), detailed binding and structural information on this ternary complex and other metal-bacitracin complexes was not presented. Furthermore, a structure-activity relationship for this antibiotic has not yet been conclusively defined.

We report herein a structural analysis of the paramagnetic $\mathrm{Co}$ (II) complexes of the antibiotic bacitracin $\mathrm{A}_{1}$ and analogues by means of NMR spectroscopy. High-spin paramagnetic $\mathrm{Co}(\mathrm{II})$ has been utilized as a very sensitive "probe" for characterizing the structure and ligand interactions of metalloproteins via the assignment of the isotropically shifted signals (16) and also serves as a nearly perfect substitute for the $\mathrm{Zn}(\mathrm{II})$ in most zinc proteins (17). The isotropically shifted ${ }^{1} \mathrm{H}$ NMR signals are attributable to protons on the ligands or the moieties near the metal, which contain structural information about the metal binding site. Thus, $\mathrm{Co}$ (II) is chosen as the prototypical metal ion for the study of the structure and function of metal-bacitracin complexes. The ligand binding mode and metal binding environment of $\mathrm{Co}(\mathrm{II})$ - bacitracin have been fully established in our study, and a structural model is built. In addition, several bacitracin analogues have also been purified or prepared and their $\mathrm{Co}$ (II) binding mode determined, which allowed us to suggest a structure-activity relationship of this antibiotic.

\section{EXPERIMENTAL PROCEDURES}

\section{A. Chemicals and Sample Preparations}

Isolation and Preparation of Bacitracin Analogues. Bacitracin mixture (50 000 units/g) was purchased from Sigma
Chemical Co. (St. Louis, MO). Several different nomenclatures have been used to classify the bacitracin analogues. In this paper, we follow the nomenclature of Ikai et al. (18). The isolation of about $10-50 \mathrm{mg}$ quantities of the different bacitracin analogues, $A_{1}, B_{1}$, and $B_{2}$, followed the literature procedures (18). An Isco model 2340 HPLC was used for the isolation, which was equipped with a semipreparative Zorbax $(\mathrm{Rx}-\mathrm{C} 8,9.4 \mathrm{~mm} \times 24 \mathrm{~cm})$ reverse-phase column, an Isco model 2361 gradient programmer, an Isco $\mathrm{V}^{4}$ absorbance detector, and a Spectra-Physics SP-4600 integrator. The bacitracin derivatives were prepared as previously described (19) with minor modifications, and isolated with reverse-phase HPLC described above (18). Fractions were collected and further analyzed with a Bruker ESQUIREelectrospray ion-trap (ESI) mass spectrometer $(0.1-1.0 \mathrm{mg} /$ $\mathrm{mL}$ in $5 \%$ acetic acid and delivered at $60 \mu \mathrm{L} / \mathrm{h}$ ), a Bruker AMX360 (360.13 MHz) and a Bruker DRX250 (250.13 MHz) NMR spectrometer, and a UV/VIS spectrophotometer. Twenty ESI spectra were averaged with each acquired at $0.2 \mathrm{~m} / \mathrm{z}$ intervals from 1000 to $1500 \mathrm{~m} / \mathrm{z}$.

Bacitracin-Metal Complexes. The metal complexes of bacitracin analogues were prepared by direct addition of 1-50 mM $\mathrm{Co}\left(\mathrm{NO}_{3}\right)_{2}$ solutions into $1-50 \mathrm{mM}$ bacitracin solutions at $\mathrm{pH} 5.0-5.5$. The $\mathrm{pH}$ of the solutions was adjusted before the addition of the metal solution to avoid precipitation. The addition of excess $\mathrm{Co}(\mathrm{II})(\sim 10$ equiv) does not significantly alter the ${ }^{1} \mathrm{H}$ NMR spectra other than increase the intensity of the signals attributable to the complex. Changing the $\mathrm{pH}$ of the samples from 4 to 5.8 also increases the intensity of the signals of the complex but does not significantly alter the chemical shift values $(<2 \mathrm{ppm})$ of the isotropically shifted signals, indicating there is no ionization occurring in that $\mathrm{pH}$ range. Samples at $\sim \mathrm{pH} 5.0$ were used for the 1D and 2D saturation transfer experiments as a more favorable exchange rate occurred between metal-bound and free bacitracin. $\mathrm{Co}$ (II) - bacitracin samples at $\mathrm{pH}$ greater than 6.0 precipitated as previously noted $(10 a)$.

\section{B. Nuclear Magnetic Resonance Experiments and Modeling}

All ${ }^{1} \mathrm{H}$ NMR spectra were acquired on the Bruker AMX360 and Bruker DRX250 spectrometers. A $90^{\circ}$ pulse with presaturation for solvent suppression was used for data (8K) acquisition of $1 \mathrm{D}{ }^{1} \mathrm{H}$ NMR spectra. The ${ }^{1} \mathrm{H}$ chemical shifts were referenced to the internal HDO signal at $4.8 \mathrm{ppm}$. A line-broadening factor of $10-30 \mathrm{~Hz}$ was introduced to the spectra via exponential multiplication prior to Fourier transformation to enhance the signal-to-noise ratio.

In paramagnetic molecules, 2D NMR techniques may be useful to establish the spatial relationship (via NOESY and ROESY) and spin systems (via TOCSY and COSY) in some cases (16). However, an attempt in utilizing these techniques for signal assignment of $\mathrm{Co}$ (II) - bacitracin was not successful. Most signals are too broad $(>150 \mathrm{~Hz})$ for TOCSY and COSY to reveal cross-peaks at both 250 and $360 \mathrm{MHz}$. The relatively small size of the complex affords a maximum NOE near the null point, and the fast relaxation rates potentially further decrease both NOE and ROE intensities. Different approaches for signal assignment thus were pursued, which are discussed below.

In the presence of chemical exchange, such as the binding of a paramagnetic metal ion to a ligand $\mathrm{L}$ to form a labile 
$\mathrm{M}-\mathrm{L}$ complex as shown below:

$$
\mathrm{M}+\mathrm{L} \rightleftharpoons \mathrm{M}-\mathrm{L}
$$

saturation transfer can occur between the exchange partners such as between the isotropically shifted signals in the paramagnetic $\mathrm{M}-\mathrm{L}$ complex and their counterparts in the diamagnetic ligand $\mathrm{L}$. This chemical exchange can be conveniently studied by means of the saturation transfer techniques used for the detection of the nuclear Overhauser effect (NOE), including 1D exchange difference spectroscopy and the 2D saturation transfer EXchange SpectroscopY (EXSY) pulse sequence $(16 b, c)$.

For the 1D saturation transfer experiments, the computer is programmed to alternately add and subtract two sets of free induction decays (FIDs) with the decoupler pulse set on a signal of interest and on a reference position for 30$80 \mathrm{~ms}$, respectively. The "super WEFT" pulse sequence (20) was employed for data acquisition of samples in $\mathrm{H}_{2} \mathrm{O}$. The difference spectra were typically run with $16 \mathrm{~K}$ data points over a range that covers the signals receiving the saturation transfer. A $0.3-10 \mathrm{~Hz}$ exponential line broadening factor was applied to the FID prior to the Fourier transformation (FT).

The 2D EXSY spectra were acquired using the same pulse sequence for the phase-sensitive NOESY experiment (such as $\mathrm{D}_{1}-90^{\circ}-\tau_{1}-90^{\circ}-\tau_{\text {mix }}-\mathrm{FID}$ ) with $1 \mathrm{~K} \times 256$ data points and a $20 \mathrm{~ms}$ mixing time. The FIDs were then zero-filled to $1 \mathrm{~K} \times 1 \mathrm{~K}$ data points and processed with a $45-60^{\circ}$ shifted sine-squared-bell window function applied in both dimensions prior to FT, followed by base line correction.

An exchange-based COSY experiment (exCOSY) was performed with the pulse sequence: $\left[\mathrm{D}_{1}-\mathrm{cw}\right.$ (on resonance)COSY $]-\left[D_{1}-\mathrm{cw}\right.$ (off resonance)-COSY $]$. The first COSY pulse train is preceded by a selective irradiation of an isotropically shifted signal using the decoupler that builds up the exchange saturation transfer. The decoupler then irradiates a reference position before the second oppositely phased COSY pulse train. Adding the two oppositely phased COSY data sets together subtracts out all of the peaks normally found in a ${ }^{1} \mathrm{H}$ COSY spectrum except the diagonal peak under exchange with the irradiated isotropically shifted signal and the associated COSY cross-peaks, thus dramatically simplifying signal assignment. The exCOSY spectra were acquired using $1 \mathrm{~K} \times 128$ data points and were processed in the magnitude mode with a $0^{\circ}$-shifted sinesquared-bell window function prior to FT.

Proton spin-lattice relaxation times $\left(T_{1}\right)$ of all the metal complexes were determined by the use of the inversionrecovery method $\left(\mathrm{D}_{1}-180^{\circ}-\tau-90^{\circ}-\mathrm{FID}\right)$ with 16 different $\tau$ values and a 3 -parameter fitting program on the spectrometer. The relaxation times of broad-overlapped signals were estimated using the null method. Because the paramagnetic contribution to the nuclear relaxation times $\left(T_{1 \mathrm{M}, 2 \mathrm{M}}\right)$ in paramagnetic metal complexes is dependent on the sixth power of the metal-nucleus distance, $r_{\mathrm{M}-\mathrm{H}}$, a large error in the $T_{1}$ measurement (e.g., $\sim 50 \%$ ) would only result in a small error in distance (i.e., $<10 \%$ ). Moreover, relative distances can be easily obtained with respect to a reference nucleus [i.e., $\left.r_{\mathrm{M}-\mathrm{H}}=\left(T_{1 \mathrm{M}} / T_{1 \mathrm{Mref}}\right)^{1 / 6} \times r_{\mathrm{M}-\mathrm{Href}}\right]$. The proton on the rigid thiazoline ring at $29.4 \mathrm{ppm}\left(T_{1}=34.4 \mathrm{~ms}\right)$ was used as the reference. The reference distance, $5.80 \AA$, was obtained by building a simple model of the metal binding site of the $\mathrm{Co}(\mathrm{II})$-bacitracin complex with the $\mathrm{Co}(\mathrm{II})-\mathrm{N}$ bond set at $2.0 \AA$ on the Cerius ${ }^{2}$ molecular modeling program (Version 3.5; Molecular Simulations, San Diego, CA).

The distances obtained from the relaxation times are utilized as constraints for building the models using the universal force field approach (21) with the Cerius ${ }^{2}$ program. In addition, torsion angles of trans peptide bonds are also added as constraints. Alternatively, a 20 ps dynamics calculation with 10 annealing cycles starting from 300 to $800 \mathrm{~K}(50 \mathrm{~K}$ increments, $1 \mathrm{fs}$ dynamics time step, and 50 steps of dynamics per increment) is performed, minimizing after each cycle which affords a slightly lower total energy (by $28 \mathrm{kcal} / \mathrm{mol}$ ). Increasing the temperature to $3000 \mathrm{~K}$ in the annealing process does not decrease the energy much. The above energy minimization processes afford structures that are not significantly different from each other, e.g., $<5 \%$ variation in distances between $1-\mathrm{NH}, 3-\mathrm{NH}$, or $4-\mathrm{NH}$ and the metal.

\section{RESULTS AND DISCUSSION}

\section{A. Characterization of Bacitracin Analogues}

The mass spectra show that the isolated bacitracin $\mathrm{A}_{1}([\mathrm{M}$ $\left.+\mathrm{H}]^{+}, m / z, 1422.8\right)$ and bacitracins $\mathrm{B}_{1}$ and $\mathrm{B}_{2}\left([\mathrm{M}+\mathrm{H}]^{+}\right.$, $m / z$ 1408.6) have the appropriate parent ion peaks similar to previous observations (7). The ${ }^{1} \mathrm{H}$ NMR spectrum of bacitracin $A_{1}$ is essentially identical to that previously reported at $\mathrm{pH} 3.2$ and $\mathrm{pH} 5.15$ (22).

Bacitracin $\mathrm{F}$ is an oxidation product of bacitracin A, with the thiazoline ring converted into a keto-thiazole group (Figure 1D), which displays a characteristic UV absorption band at $290 \mathrm{~nm}$ due to the thiazole ring (23). The ${ }^{1} \mathrm{H}$ NMR spectrum of bacitracin $\mathrm{F}$ (not shown) is quite distinct from that of $A_{1}$, in which one new signal at $8.4 \mathrm{ppm}$ is detected due to the proton of the newly formed thiazole ring. In addition, the thiazoline ring signals at 5.2, 3.75, and 3.55 ppm and the Ile- $1 \alpha$ proton at $4.26 \mathrm{ppm}$ in $\mathrm{A}_{1}$ are lost in this transformation, along with a noted downfield shift for the Ile-1 $\beta$ proton (to $3.75 \mathrm{ppm}$ ) which is adjacent to the newly formed electron-withdrawing carbonyl group in bacitracin $\mathrm{F}$. The mass spectrum of bacitracin $\mathrm{F}$ revealed the loss of three protons $\left([\mathrm{M}+\mathrm{H}]^{+}, 1419.4 \mathrm{~m} / \mathrm{z}\right)$, two thiazoline ring protons, and the $\alpha$ proton of Ile- 1 .

Bacitracin $A_{2}$ is made via an acid-catalyzed epimerization of the L-Ile-1 of bacitracin $\mathrm{A}_{1}$ to a D-allo-Ile-1 (Figure 1B). These two stereoisomers exhibit identical ${ }^{1} \mathrm{H}$ NMR spectra and the same molecular weight $\left([\mathrm{M}+\mathrm{H}]^{+}, m / z\right.$ 1422.8). However, a significant difference between these two isomers can be observed in the isotropically shifted ${ }^{1} \mathrm{H}$ NMR features (see later) upon formation of $\mathrm{Co}$ (II) complexes, indicating the robustness of the paramagnetic $\mathrm{Co}(\mathrm{II})$ "probe" for structural analysis of bacitracin analogues.

\section{B. Assignment of the Isotropically Shifted ${ }^{1} H$ NMR Features of Cobalt(II)-Bacitracin Complexes in Water}

High-Potency $C o(I I)-$ Bacitracins $A_{1}, B_{1}$, and $B_{2}$. Upon addition of 1 equiv of $\mathrm{Co}$ (II) to bacitracin mixture, a complex is formed which exhibits about 20 isotropically shifted ${ }^{1} \mathrm{H}$ NMR signals in a spectral window of 200 ppm (Figure 2). The solvent-exchangeable NH signals are readily identified 


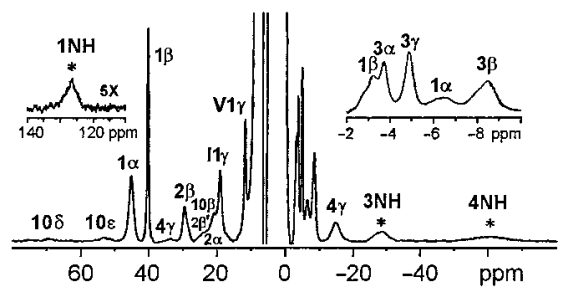

FIGURE 2: ${ }^{1} \mathrm{H}$ NMR spectra $(250.13 \mathrm{MHz}$ at ambient temperature) of the $\mathrm{Co}$ (II) complex of bacitracin mixture (ca. $25 \mathrm{mM}$ at $\sim \mathrm{pH}$ 5.4). The labels indicate the amino acid sequence (1-12, Figure $1)$ and the positions of the protons in the amino acid ( $\alpha, \beta$, etc.). Asterisks indicate solvent-exchangeable signals. The peak at 11.7 ppm $(\mathrm{V} 1 \gamma)$ corresponds to the Val-1 $\gamma$ protons of bacitracin $\mathrm{B}_{2}$ found in the bacitracin mixture. Peak positions vary slightly $(<2$ $\mathrm{ppm}$ ) with sample concentration and $\mathrm{pH}$ in a range from 4 to 5.8 .

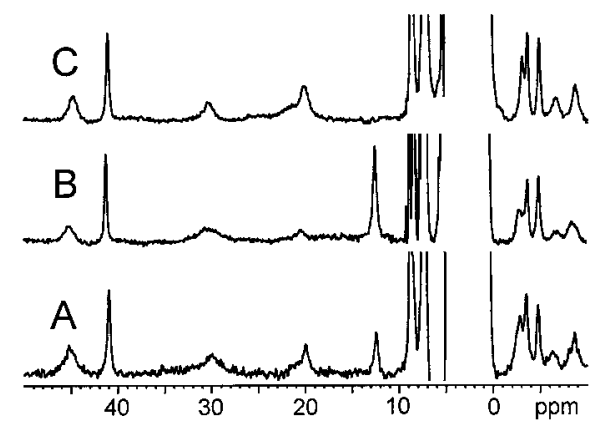

FIGURE 3: ${ }^{1} \mathrm{H}$ NMR spectra (250.13 MHz at ambient temperature) of the $\mathrm{Co}$ (II) complexes (ca. $2 \mathrm{mM}$ at $\mathrm{pH}$-meter reading $\mathrm{pH}^{*}=$ 5.4 in $\mathrm{D}_{2} \mathrm{O}$ ) of $(\mathrm{A})$ bacitracin mixture, $(\mathrm{B})$ bacitracin $\mathrm{B}_{1}$, and $(\mathrm{C})$ bacitracin $A_{1}$. The complete spectrum of $(A)$ in $\mathrm{H}_{2} \mathrm{O}$ is shown in Figure 2. The isotropically shifted ${ }^{1} \mathrm{H}$ NMR features of $\mathrm{Co}(\mathrm{II})-$ bacitracin $\mathrm{B}_{2}$ (Ile-5 $\rightarrow$ Val-5) are identical to those of $\mathrm{Co}(\mathrm{II})-$ bacitracin $A_{1}$.

as they disappear in $\mathrm{D}_{2} \mathrm{O}$ solutions. The ${ }^{1} \mathrm{H}$ NMR spectrum of a freshly prepared 1:1 Co(II) complex of bacitracin mixture in $\mathrm{D}_{2} \mathrm{O}$ is shown in Figure 3 (spectrum A), along with the spectra of $\mathrm{Co}(\mathrm{II})$-bacitracin $\mathrm{B}_{1}$ (B) and $\mathrm{Co}(\mathrm{II})-$ bacitracin $\mathrm{A}_{1}(\mathrm{C})$. The isotropically shifted ${ }^{1} \mathrm{H}$ NMR features of $\mathrm{Co}$ (II)-bacitracin $\mathrm{B}_{2}$ (Ile-5 $\rightarrow$ Val-5) are identical to those of $\mathrm{Co}(\mathrm{II})$-bacitracin $\mathrm{A}_{1}$ and are not repeated here. This observation indicates that Ile-5 does not perturb the structure of the metal binding site, and thus is not near the metal.

All three ${ }^{1} \mathrm{H}$ NMR spectra in Figure 3 display identical isotropically shifted features except for the signals at 12.2 ppm observed in $\mathrm{Co}(\mathrm{II})$-bacitracin $\mathrm{B}_{1}$, and $19.8 \mathrm{ppm}$ in $\mathrm{Co}$ (II)-bacitracin $\mathrm{A}_{1}$ (partially overlapped with a broad peak at $\sim 20 \mathrm{ppm}$ ). Since the only structural difference is the Ile-1 of bacitracin $\mathrm{A}_{1}$ and the Val-1 of bacitracin $\mathrm{B}_{1}$ (Figure 1), the signal at $12.2 \mathrm{ppm}$ can be assigned to the Val-1 $\gamma-\mathrm{CH}_{3}$ of bacitracin $\mathrm{B}_{1}$ while the $19.8 \mathrm{ppm}$ signal can be assigned to a Ile- $1 \gamma-\mathrm{CH}_{2}$ proton of bacitracin $\mathrm{A}_{1}$. The detection of these signals suggests that the $\mathrm{N}$-terminus is close to the $\mathrm{Co}(\mathrm{II})$ ion. Other shifted signals in the two spectra are virtually identical, indicating a nearly identical metal environment. The structural resemblance of the metal environment of the three bacitracin analogues, $\mathrm{A}_{1}, \mathrm{~B}_{1}$, and $\mathrm{B}_{2}$, may reflect their similar high antibiotic activities.

EXSY Spectrum of Co(II)-Bacitracin Mixture. Despite the presence of an equilibrium between the Co(II)-bound and free forms of the drug, isotropically shifted ${ }^{1} \mathrm{H}$ NMR features are clearly detected for the complexes which are well separated from the signals of the free drug. The complexes

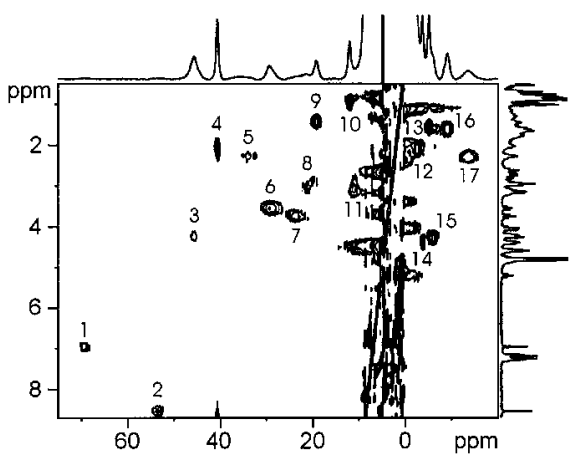

FIGURE 4: ${ }^{1} \mathrm{H}$ EXSY spectrum (250.13 MHz, $298 \mathrm{~K}$, mixing time $20 \mathrm{~ms}$, and a recycle time of $230 \mathrm{~ms}$ ) of the Co(II) complex of bacitracin mixture in $\mathrm{D}_{2} \mathrm{O}$ which shows a correlation between the hyperfine-shifted signals of the $\mathrm{Co}$ (II) complex with the diamagnetic signals of the metal-free form of the drug [i.e., $\mathrm{Co}(\mathrm{II})$-bacitracin $\leftrightarrow \mathrm{Co}$ (II) + bacitracin]. Signals 1 and 2 can be clearly assigned to the His- $10 \mathrm{C}_{\epsilon} \mathrm{H}$ and $\mathrm{C}_{\delta} \mathrm{H}$ protons, respectively, and signals 6 and 7 can be assigned to the well-resolved diamagnetic Cys- $2 \beta$ protons. Signals 5 and 17 can be unequivocally assigned to the Glu- $4 \gamma$ protons. The other signals cannot be unequivocally assigned in this spectrum.

can thus be unambiguously studied via the shifted signals. Since the Co(II)-bound bacitracin is under chemical exchange with its free form, signal assignment of the Co(II)-bacitracin complex can be achieved by the use of $1 \mathrm{D}$ and 2D saturation transfer techniques as in the studies of other metal-antibiotic systems $(3,24)$. The EXSY spectrum shows 17 pairs of cross-peaks between the isotropically shifted signals of the $\mathrm{Co}(\mathrm{II})$-bacitracin complex and the diamagnetic signals of the metal-free bacitracin (Figure 4). The bacitracin mixture was used in most of the NMR experiments as samples with higher concentrations could be easily made, facilitating the detection of broad features, such as the signals at 70 and 53 $\mathrm{ppm}$. A few of the cross-peaks are resolved enough to be unambiguously assigned, including the His-10 ring $\mathrm{C}_{\delta} \mathrm{H}$ and $\mathrm{C}_{\epsilon} \mathrm{H}$ protons (1 and 2, Figure 4), the Glu-4 $\gamma-\mathrm{CH}_{2}$ protons (5 and 17), and the Cys- $2 \beta-\mathrm{CH}_{2}$ protons ( 6 and 7 ). The fast exchange rate enables us to identify a few very broad signals in the EXSY spectrum, including signals 1, 2, 5, 7, and 8 which otherwise can be simply overlooked. The poor resolution of the rest of the cross-signals in the EXSY spectrum prevented an unambiguous assignment. Nevertheless, the assignment of all the isotropically shifted signals (Table 1) has been achieved by the use of several other 1D and 2D NMR techniques. In the following sections, the assignments of isotropically shifted signals are discussed according to different functional groups for clarity.

Thiazoline Ring (Cys-2) Signals. One-dimensional saturation transfer difference experiments conclude the thiazoline ring assignments, in which the signals at 20.9, 29.4, and 23.6 ppm show saturation transfer peaks to the characteristic and well-defined thiazoline ring methyne proton (Cys-2 $\alpha$ proton) and the two Cys- $2 \beta$ proton signals (Figure 5, Table 1). A partial overlap of the Cys- $2 \alpha$ proton signal with the Cys-2 $\beta$ signal and a His-10 $\beta$ signal (see later) results in the detection of three saturation transfer peaks.

Relative metal-proton distances can be obtained from the distance-dependent paramagnetic contribution to the $T_{1}$ relaxation rate (see Experimental Procedures) (16, 25). For example, the Cys- $2 \beta$ proton at $29.4 \mathrm{ppm}$ is further away from the $\mathrm{Co}$ (II) ion than the Cys- $2 \alpha$ proton and the other 
Table 1: Chemical Shifts and $T_{1}$ Values of the Isotropically Shifted Signals of $\mathrm{Co}^{2+}$ Complexes of Bacitracins $\mathrm{A}_{1}$ and $\mathrm{A}_{2}$ and the $T_{1}$-Based $\mathrm{Co}^{2+}-\mathrm{H}$ Distances

\begin{tabular}{|c|c|c|c|c|c|c|c|c|}
\hline assignment & $\begin{array}{l}\mathrm{Co}^{2+}-\mathrm{A}_{1} \\
(\mathrm{ppm} / \mathrm{ms})^{a}\end{array}$ & $\begin{array}{c}\text { free } A_{1} \\
(\mathrm{ppm})\end{array}$ & $\begin{array}{c}\mathrm{Co}^{2+}-\mathrm{H}^{b} \\
(\AA)\end{array}$ & $\begin{array}{l}\mathrm{Co}^{2+}-\mathrm{A}_{2} \\
(\mathrm{ppm} / \mathrm{ms})^{a}\end{array}$ & assignment & $\begin{array}{l}\mathrm{Co}^{2+}-\mathrm{A}_{1} \\
(\mathrm{ppm} / \mathrm{ms})^{a}\end{array}$ & $\begin{array}{c}\text { free } A_{1} \\
(\mathrm{ppm})\end{array}$ & $\begin{array}{c}\mathrm{Co}^{2+}-\mathrm{H}^{b} \\
(\AA)\end{array}$ \\
\hline $1-\mathrm{NH}$ & $125 / c$ & $d$ & $(2.87)^{e}$ & & $3 \gamma$ & $-4.9 / 66.4$ & 1.54 & $6.47(6.50)$ \\
\hline $1_{\alpha}$ & $45.1 / 2.9$ & 4.26 & $3.84(3.80)$ & $52 / 2.5$ & $4-\mathrm{NH}$ & $-60.8 / b$ & 8.73 & $(4.27)^{e}$ \\
\hline $1_{\beta}$ & $40.2 / 19.9$ & 2.05 & $5.29(5.29)$ & $44 / 5.2$ & $4_{\alpha}$ & $-6.4 / 82.1$ & 4.26 & $6.71(6.68)$ \\
\hline $1 \gamma^{f}$ & $19 / 14.2$ & 1.43 & $5.00(5.00)$ & & $4_{\beta}$ & $-3.2 / 51.4$ & 2.05 & $6.20(6.20)$ \\
\hline $2 \alpha$ & $\sim 21 / \sim 3.4^{g}$ & 5.22 & $3.94(3.85)$ & 21.5 & $4 \gamma$ & $34 / 6.1$ & 2.45 & $4.35(4.83)$ \\
\hline $2 \beta$ & $29.4 / 34.4$ & 3.55 & $5.80^{h}(5.72)$ & 29.5 & $4 \gamma^{\prime}$ & $-14.8 / 19.9$ & 2.45 & $5.29(5.25)$ \\
\hline $2 \beta^{\prime}$ & $23.6 / 6.5$ & 3.76 & $4.39(4.44)$ & & $6_{\epsilon}$ & $\sim 21 / \sim 3.4^{g}$ & 3.17 & $3.94(4.10)$ \\
\hline $3-\mathrm{NH}$ & $-28.9 / b$ & 8.08 & $(4.24)^{e}$ & & $10_{\delta}^{i}$ & $69.4 / \mathrm{c}$ & 6.98 & $(3.45 / 3.10)$ \\
\hline $3_{\alpha}$ & $-3.7 / 49.7$ & 4.4 & $6.17(6.12)$ & -4 & $10_{\epsilon}^{i}$ & $53.3 / \mathrm{c}$ & 8.56 & $(3.10 / 3.45)$ \\
\hline $3_{\beta}$ & $-8.5 / 24.7$ & 1.64 & $5.49(5.48)$ & -7 & & & & \\
\hline
\end{tabular}

${ }^{a}$ Chemical shift $(\mathrm{ppm})$ and $T_{1}$ values $(\mathrm{ms}) .{ }^{b}$ The $T_{1}$-based distances are obtained according to $r_{\mathrm{H}-\mathrm{M}}=r_{\text {ref-M }} \times\left(T_{1} / T_{1 \text { ref }}\right)^{1 / 6}$, with the initial reference $\mathrm{Co}-2 \beta$ distance of $5.80 \AA$. The distances in the final model are reported in parentheses (Figure $9 \mathrm{~A}$ ). ${ }^{c}$ The signal is too broad and far-shifted to afford consistent $T_{1}$ values. ${ }^{d}$ This signal in the metal-free bacitracin is not detected, which may be due to its fast exchange with the bulk water protons under the experimental conditions. ${ }^{e}$ The broadness of the signal is due to the short distances to Co(II). In addition, their exchange with the bulk water proton may also broaden the signal. ${ }^{f}$ The only significant difference between the Co(II)-bacitracin $\mathrm{A}_{1}$ and Co(II)-bacitracin $\mathrm{B}_{1}$ spectra is the $1_{\gamma}$ proton, which is found at $11.7 \mathrm{ppm}$ and $T_{1}=69 \mathrm{~ms}$, corresponding to a Co(II) $-\mathrm{H}$ distance of $6.5 \AA$ in $\mathrm{Co}$ (II) - bacitracin $\mathrm{B}_{1}{ }^{g}{ }^{g}$ The signals are overlapped (but revealed in the difference spectrum in Figure 4), and the $T_{1}$ values were estimated with the null method. ${ }^{h}$ This proton serves as the "reference" proton which is set to be $5.80 \AA$ away from the Co(II). ${ }^{i}$ The His signals are the only detectable isotropically shifted signals in $\mathrm{Co}(\mathrm{II})$-bacitracin $\mathrm{F}$.

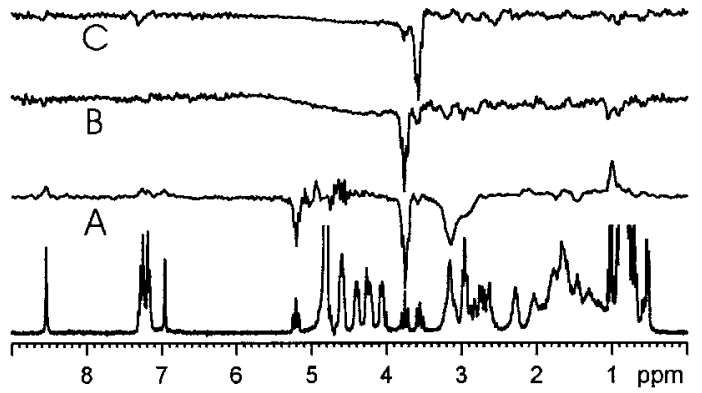

FIGURE 5: One-dimensional saturation transfer experiments $(250$ $\mathrm{MHz}$, ambient temperature) on $\mathrm{Co}(\mathrm{II})$-bacitracin using a $50 \mathrm{~ms}$ presaturation pulse on signals at $20.9 \mathrm{ppm}(\mathrm{A}), 23.6 \mathrm{ppm}(\mathrm{B})$, and $29.4 \mathrm{ppm}(\mathrm{C})$. The detection of saturation transfer between these hyperfine-shifted signals to the diamagnetic signals at 5.2, 3.75, and $3.55 \mathrm{ppm}$, respectively, facilitates their assignment to the Cys-2 $\alpha, \beta$, and $\beta^{\prime}$ protons. Signals at 20.9 and $23.6 \mathrm{ppm}$ and a His-10 $\beta$ proton overlap which produce three exchange signals in (A).

Cys- $2 \beta$ proton (Table 1). This distance information indicates that the $\mathrm{Co}$ (II) ion binds to the thiazoline ring via the nitrogen atom, similar to the $\mathrm{Cu}(\mathrm{II})$ binding mode suggested in an EPR study (10b), but not via the sulfur atom as suggested in another earlier study (11) which would show much shorter $T_{1}$ values for the $\beta$ protons than the $\alpha$ proton.

His-10 Signals. The chemical shifts of the $\mathrm{C}_{\epsilon} \mathrm{H}$ and $\mathrm{C}_{\delta} \mathrm{H}$ protons of His-10 assigned in the EXSY spectrum (2 and 1, Figure 4) are in the region consistent with Co(II)-bound histidine in several metalloproteins (26). Both signals are broad, supporting an $\mathrm{N}_{\epsilon}$ binding mode since a relatively sharp $\mathrm{C}_{\delta} \mathrm{H}$ signal would be observed for a $\mathrm{N}_{\delta}$-coordinated histidine $(16,26)$. The ring $\mathrm{NH}$ proton is not detected, which can be due to its fast solvent exchange rate as in the case of a few Co(II)-substituted proteins (16).

The hyperfine shifted signal at $21 \mathrm{ppm}$ (overlapped with the Cys- $2 \alpha$ proton) gives a saturation transfer peak at 3.15 ppm, presumably due to a His-10 $\beta$ proton as mentioned above (Figure 5A). The Lys- $6 \mathrm{C}_{\epsilon} \mathrm{H}_{2}$ protons overlapped at $3.15 \mathrm{ppm}$ are also possible candidates for this shifted signal. The relaxation time seems to be more consistent with the latter assignment (Table 1). However, the broadness of the diamagnetic counterpart prevents further assignment.

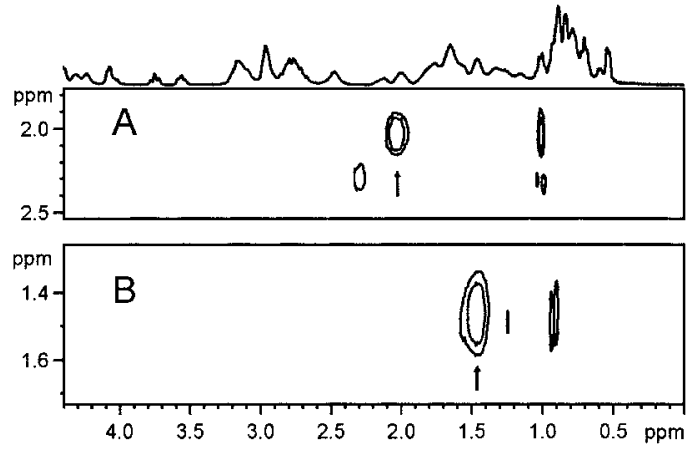

FIGURE 6: ${ }^{1} \mathrm{H}$ exchange-based COSY (exCOSY) spectrum of $\mathrm{Co}(\mathrm{II})$-bacitracin complex using a $100 \mathrm{~ms}$ decoupler pulse to irradiate the signals at $40.2 \mathrm{ppm}$ (A) and at $19 \mathrm{ppm}$ (B). The acquisition time is $141 \mathrm{~ms}$ with a total recycle time of $750 \mathrm{~ms}$. The diagonal saturation transfer peaks due to the chemical exchange at 2.05 (A) and 1.4 (B) ppm are marked with arrows. The crosspeak at $1.03 \mathrm{ppm}$ in (A) is attributable to the $\gamma-\mathrm{CH}_{3}$ of Ile-1, and the two cross-peaks at 0.92 and $0.88 \mathrm{ppm}$ in (B) correspond to the Ile- $1 \gamma-\mathrm{CH}^{\prime}$ and $\delta-\mathrm{CH}_{3}$ protons, respectively.

Ile-1 Signals. Assignment of Ile-1 shifted signals cannot be achieved by means of saturation transfer owing to signal overlap in the diamagnetic region. For example, the signal at $40.2 \mathrm{ppm}$ shows saturation transfer to the signal at 2.05 ppm, due to either the Ile- $1 \beta$ proton or the Glu- $4 \beta$ proton of the free drug. The exchange-based COSY (exCOSY) pulse sequence reveals that the $40.2 \mathrm{ppm}$ signal displays a saturation transfer peak to its diamagnetic counterpart at 2.05 ppm (the "diagonal signal" marked with an arrow, Figure 6A) and a COSY cross-peak at $1.03 \mathrm{ppm}$ attributable to the $\gamma$-methyl of Ile- 1 (whereas the $\alpha$ and $\gamma$ protons of Glu- 4 are at 4.26 and $2.45 \mathrm{ppm}$ under the experimental conditions). Thus, this $40.2 \mathrm{ppm}$ signal can be assigned to the Ile- $1 \beta$ proton. The COSY spectrum of metal-free bacitracin reveals a strong interaction between the Ile- $1 \beta-\mathrm{CH}$ and $\gamma-\mathrm{CH}_{3}$ protons (spectrum not shown), confirming the assignment. The $19 \mathrm{ppm}$ hyperfine shifted signal can be assigned to an Ile-1 $\gamma$-CH proton in a similar fashion (Figure 6B, Table 1). This confirms the assignment as noted above in the comparison of the ${ }^{1} \mathrm{H}$ NMR spectra of $\mathrm{Co}(\mathrm{II})$ complexes of bacitracins $\mathrm{A}_{1}$ and $\mathrm{B}_{1}$ (Figure 3 ). 


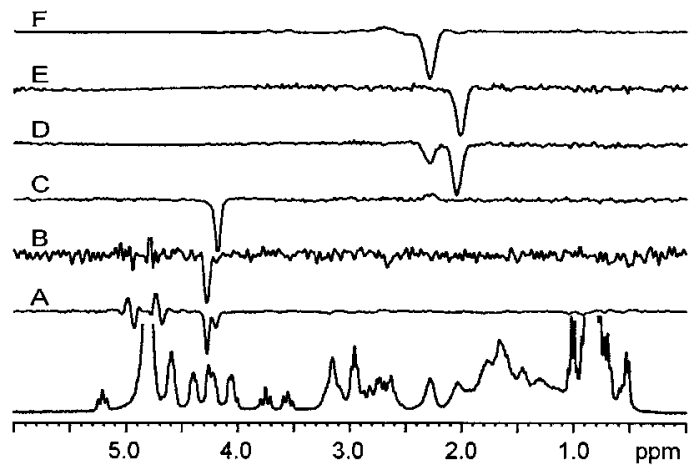

FIGURE 7: One-dimensional saturation transfer difference experiments (250 MHz, ambient temperature) on the isotropically shifted signals at 45.1 and $40.2 \mathrm{ppm}$, attributable to Ile-1/Val- $1 \alpha$ and Ile/ Val-1 $\beta$ protons, respectively, in the $\mathrm{Co}$ (II) complex of bacitracin mixture (A and D), Co(II)-bacitracin $\mathrm{A}_{1}$ (B and E), and $\mathrm{Co}(\mathrm{II})-$ bacitracin $\mathrm{B}_{1}(\mathrm{C}$ and $\mathrm{F})$.

Both the signals at 45.1 and $-6.4 \mathrm{ppm}$ give saturation transfer to a diamagnetic signal at $4.26 \mathrm{ppm}$ (however, see below), corresponding to the $\alpha$ proton of either Ile- 1 or Glu4. An exCOSY experiment could not identify these two signals as their adjacent $\beta$ proton signals are also overlapped at $2.05 \mathrm{ppm}$. Thus, a different approach has been taken. The $45.1 \mathrm{ppm}$ signal for the Co(II)-bacitracin mixture gives two saturation transfer peaks at 4.26 and $4.18 \mathrm{ppm}$ (Figure 7A) while the signal at $-6.4 \mathrm{ppm}$ gives only one at $4.26 \mathrm{ppm}$. Two peaks are expected for the $\mathrm{N}$-terminus $\alpha$ proton in the bacitracin mixture as bacitracin $\mathrm{B}_{1}$ has a Val- $1 \alpha$ proton at $4.18 \mathrm{ppm}$, and $\mathrm{A}_{1}$ has an Ile-1 $\alpha$ proton at $4.26 \mathrm{ppm}$. However, only one peak is found at $4.26 \mathrm{ppm}$ for the Glu- 4 $\alpha$ proton in both analogues. The $45.1 \mathrm{ppm}$ signal can thus be assigned to the Ile-1/Val-1 $\alpha$ proton. This signal displays only one cross-peak to the $4.26 \mathrm{ppm}$ signal in $\mathrm{Co}$ (II)bacitracin $\mathrm{A}_{1}$ (spectrum 7B) and only to the $4.18 \mathrm{ppm}$ signal in $\mathrm{Co}(\mathrm{II})$-bacitracin $\mathrm{B}_{1}$ (spectrum $7 \mathrm{C}$ ), confirming the assignment. Similarly, the signal at $40.2 \mathrm{ppm}$ in the Co(II)bacitracin mixture can be assigned to Ile- $1 \beta$ proton (spectra 7D-F, Table 1). The $\alpha$ and $\beta$ protons in the Co(II) complexes of bacitracins $\mathrm{A}_{1}$ and $\mathrm{B}_{1}$ have the same chemical shifts, indicating that they are located at the same place with respect to the $\mathrm{Co}(\mathrm{II})$ in these two complexes.

The furthest downfield isotropically shifted signal at 125 ppm (inset, Figure 2) is solvent-exchangeable and has to be assigned to a labile proton close to the Co(II) ion. Since the $\mathrm{NH}$ protons of Leu-3, Glu-4, and His-10 that are near the metal binding site have all been assigned (see later; Table 1 ), the $125 \mathrm{ppm}$ signal is tentatively assigned to the Ile- 1 $\alpha-\mathrm{NH}_{2}$ protons by default, which is very close to the metal (see Section D and Table 1). Since its diamagnetic counterpart is not detected in the diamagnetic region possibly due to fast solvent exchangeability, saturation transfer is not observed.

The $-\mathrm{NH}_{2}$ protons of $\mathrm{Co}(\mathrm{II})$-coordinated amines show large upfield-shifted ${ }^{1} \mathrm{H}$ NMR signals ( -150 to $-200 \mathrm{ppm}$ ) (27), while Ile- $1 \mathrm{NH}_{2}$ protons are downfield-shifted. Furthermore, the $\alpha$ and $\beta$ protons of coordinated amines and amino acids display well-separated signals $(\sim 200 \mathrm{ppm}$ in some cases) as a result of the spin polarization mechanism (28), whereas the Ile- $1 \alpha$ and $\beta$ protons have similar isotropic shifts (Table 1). In addition, the amino group of Ile-1 is protonated at $\mathrm{pH} 4$ in the presence of metal ion with $\mathrm{p} K_{\mathrm{a}}=$
5.7 (10a); thus, it cannot be bound to the Co(II) ion at $\mathrm{pH} 4$. The overall spectral features for the Co(II)-bacitracin complex are almost identical at $\mathrm{pH} 4-5.8$ with similar chemical shifts (differ by $<2 \mathrm{ppm}$ ), also suggesting that the Ile-1 amine is not bound to the $\mathrm{Co}(\mathrm{II})$ in that $\mathrm{pH}$ range.

Leu-3 Signals. The isotropically shifted signal at $-3.7 \mathrm{ppm}$ gives a saturation transfer peak to an $\alpha$ proton signal at 4.4 ppm for either Leu-3 or Orn-7. This signal is assigned to the Leu-3 $\alpha$ protons using the exCOSY spectrum which reveals cross-peaks to signals at 1.66 and $1.56 \mathrm{ppm}$ due to the Leu-3 $\beta$ and $\gamma$ protons (Figure S1A, Supporting Information). Similarly, the signal at $-8.5 \mathrm{ppm}$ with a saturation transfer peak at 1.66 ppm (due to the Leu- $3 \beta$, Lys- $6 \beta$, Orn-7 $\gamma$, or Ile- $8 \beta$ proton) can be assigned to a $\beta$ proton of Leu- 3 ; and the signal at $-4.9 \mathrm{ppm}$ assigned to the Leu-3 $\gamma$ proton (Figure S1B,C). The solvent-exchangeable signal at -28.9 ppm gives a clear saturation transfer peak to the Leu-3 NH signal at $7.98 \mathrm{ppm}$ in a WEFT difference spectrum at 50 ${ }^{\circ} \mathrm{C}$, distinguished from the overlapped Orn-7 $\mathrm{NH}$ signal at $25^{\circ} \mathrm{C}$ (spectra not shown). This completes the assignment of the Leu-3 protons (Table 1).

An upfield hyperfine-shifted ${ }^{1} \mathrm{H}$ NMR signal and a small $T_{1}$ value $(<5 \mathrm{~ms})$ are generally noted for amido-oxygencoordinated amide $\mathrm{NH}$ and $\alpha$ protons in $\mathrm{Co}(\mathrm{II})$-substituted proteins and amino acid complexes (29). This suggests that the Cys-2/Leu-3 amido-oxygen may be involved in Co(II) binding, although the presence of the dipolar shift mechanism makes this less conclusive.

Glu-4 Signals. The signal at -6.4 and $-3.2 \mathrm{ppm}$ exhibits saturation transfer to signals at 4.26 and $2.05 \mathrm{ppm}$ due to Glu-4/Ile-1 $\alpha$ proton and Glu-4/Ile-1 $\beta$ proton, respectively (Figure S2A,B, Supporting Information). Since the Ile-1 protons have already been assigned (Table 1 ), the two signals can thus be assigned to the Glu- $4 \alpha$ and $\beta$ protons by default. The assignment has also been confirmed by an exCOSY experiment. The isotropically shifted signals at 34 and -14.8 ppm show the same saturation transfer peak to the diamagnetic glutamate $\gamma$ signal at $2.35 \mathrm{ppm}$ (cross-peaks 5 and 17 in Figure 4; Figure S2C,D), and are thus assigned. The far upfield-shifted solvent-exchangeable signal at $-60.8 \mathrm{ppm}$ with saturation transfer to the diamagnetic Glu-4 NH signal can also be assigned (Figure S2E). This completes the assignment of the isotropically shifted Glu-4 signals (Table 1) which indicates that the $\gamma$-carboxylate of Glu-4 is bound to the metal, corroborating previous suggestions $(10 b, 11)$.

The Glu- 4 can bind to the metal as a monodentate or a bidentate ligand, which could not be differentiated in previous studies. A bidentate binding mode would afford similar $\mathrm{H}-\mathrm{Co}$ distances for the two $\gamma$ protons. The very different $T_{1}$ values for the geminal $\gamma$ protons indicate that this is not the case. The proton at $-14.8 \mathrm{ppm}$ is possibly in an equatorial position with respect to the $\mathrm{Co}(\mathrm{II})-\mathrm{O}=\mathrm{C}$ plane, experiencing an upfield shift via the spin polarization mechanism $(16,28,30)$, while the other $\gamma$ proton $(34 \mathrm{ppm})$ may be in an axial position which gains a significant downfield hyperfine shift via a spin hyperconjugation mechanism (28) through the delocalized carboxylate $\pi$-orbitals. A model built with the $T_{1}$-based distance constraints corroborates this conclusion (Table 1). Furthermore, the overall spin pattern of Glu-4 is very similar to the $\mathrm{O}_{\epsilon}$-coordinated Gln ligand in the $\mathrm{Co}$ (II)-substituted M121Q azurin mutant (29b), also suggesting that Glu-4 is bound to the Co(II) ion 


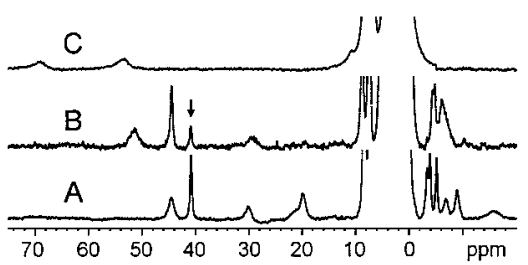

FIGURE 8: ${ }^{1} \mathrm{H}$ NMR spectra $(250.13 \mathrm{MHz}$ at $298 \mathrm{~K})$ of the $\mathrm{Co}(\mathrm{II})$ complexes (ca. $2 \mathrm{mM}$ at $\mathrm{pH}$-meter reading $\sim 5.4$ in $\mathrm{D}_{2} \mathrm{O}$ ) of (A) bacitracin $\mathrm{A}_{1}$, (B) bacitracin $\mathrm{A}_{2}$, and $(\mathrm{C})$ bacitracin $\mathrm{F}$ (at $\mathrm{pH}$ 7.5). The arrow in (B) indicates some residual bacitracin $A_{1}$.

as a monodentate ligand via one carboxylate oxygen as in the case of the M121Q azurin.

The large upfield shift and broadness of the Glu-4 NH proton indicate that it is very close to the $\mathrm{Co}$ (II) ion. The upfield shift could occur through either a spin polarization mechanism or a dipolar interaction depending on whether the Leu-3 peptide carbonyl is coordinated to the $\mathrm{Co}$ (II) ion. The large number of upfield-shifted signals in the ${ }^{1} \mathrm{H}$ NMR spectrum of the complex favors the dipolar mechanism. Moreover, a model built based on $T_{1}$ constraints shows an unbound Leu-3 peptide carbonyl (see section D).

All the isotropically shifted signals have been unambiguously assigned to Ile-1, Cys-2 (thiazoline), Leu-3, Glu-4, and His-10 at this stage. There is no indication of any other coordinated ligand based on this assignment. Thus, the possibility of a bound Asp-11 suggested in a previous study (10b) can be excluded. The metal binding ligands are thus concluded to be the thiazoline nitrogen, the monodentate Glu-4 $\gamma$-carboxylate, and the His-10 $\epsilon$-nitrogen.

\section{C. ${ }^{1}$ H NMR Spectra of Cobalt(II) Complexes of Other Bacitracin Analogues}

Co(II)-Bacitracin $A_{2}$. The ${ }^{1} \mathrm{H}$ NMR spectrum of $\mathrm{Co}(\mathrm{II})-$ bacitracin $\mathrm{A}_{2}$ is presented in Figure $8 \mathrm{~B}$, which shows similarities and significant changes when compared with the spectrum of $\mathrm{Co}$ (II)-bacitracin $\mathrm{A}_{1}$ (spectrum A). While the Leu- 3 and the thiazoline ring signals are not significantly affected by the change of the stereochemistry, the Ile-1 $\alpha$ and $\beta$ protons are dramatically affected in $\mathrm{Co}(\mathrm{II})$-bacitracin $\mathrm{A}_{2}$ (cf. Table 1). The larger hyperfine chemical shifts and shorter $T_{1}$ values for the $\alpha / \beta$ protons of the D-allo-Ile- 1 in $\mathrm{Co}(\mathrm{II})$-bacitracin $\mathrm{A}_{2}$ indicate that they are closer to the $\mathrm{Co}$ (II) ion than the L-Ile- $1 \alpha / \beta$ protons in $\mathrm{Co}(\mathrm{II})$-bacitracin $\mathrm{A}_{1}$. Moreover, the Ile- $1 \gamma-\mathrm{CH}_{2}$ protons are not detected in $\mathrm{Co}$ (II)-bacitracin $\mathrm{A}_{2}$, indicating that this group is located at a quite different position from its counterpart in $\mathrm{Co}$ (II)bacitracin $A_{1}$ with respect to the metal. Changes in the ${ }^{1} \mathrm{H}$ NMR signals corresponding to the Ile-1 protons are expected since bacitracins $A_{2}$ and $A_{1}$ differ only at the N-terminus (Figure 1).

All the Glu-4 signals are missing in the spectrum of $\mathrm{Co}$ (II)-bacitracin $\mathrm{A}_{2}$, indicating that the carboxylate side chain does not bind to $\mathrm{Co}(\mathrm{II})$. This observation reflects that the Ile- $1 \mathrm{NH}_{3}{ }^{+}$moiety of $\mathrm{Co}(\mathrm{II})$-bacitracin $\mathrm{A}_{1}$ may interact with Glu-4, likely via the unbound $\mathrm{O}_{\epsilon}$, as well as potentially form a hydrogen bond with the peptide carbonyl of Asn-12 (see section D), and the change of Ile-1 stereochemistry possibly interferes with the binding of the Glu-4 carboxylate to the $\mathrm{Co}$ (II) ion. Furthermore, the Phe-9/Ile-5 hydrophobic pocket (section D) may also be affected as a result of losing the Glu-4 ligand (increasing by $\sim 3 \AA$ ). These variations in the specific intramolecular interactions may be part of the reasons for the decreased biological activity of bacitracin $\mathrm{A}_{2}$.

Bacitracin $\mathrm{A}_{2}$ was originally called the "low potency" bacitracin A when it was first made $(19 b, 31)$. Although it was never completely purified by the countercurrent distribution techniques employed at that time, a dramatic decrease in its activity was still clearly observed when compared with the activity of bacitracin $A_{1}$. This decreased potency may now be explained by the significant changes that occur to the metal binding site of bacitracin. The modification of the stereochemistry of L-Ile-1 that is not directly involved in metal binding can indeed result in a large change in the metal binding environment of bacitracin. On the other hand, all the highly active bacitracin analogues, $\mathrm{A}_{1}, \mathrm{~B}_{1}$, and $\mathrm{B}_{2}$, have similar metal binding sites as shown by their similar isotropically shifted ${ }^{1} \mathrm{H}$ NMR features (Figure 3).

Co(II)-Bacitracin F. Bacitracin F (Figure 1D) does not produce a characteristic ${ }^{1} \mathrm{H}$ NMR spectrum in the presence of $\mathrm{Co}$ (II) under the same conditions for the preparation of the $\mathrm{Co}$ (II) complexes of the other bacitracin analogues. This observation indicates that $\mathrm{Co}$ (II) does not bind to bacitracin F under those conditions, and that both the thiazoline ring and the Ile- $1 \mathrm{NH}_{3}{ }^{+}$are required for the formation of a stable metal-bacitracin complex. The thiazole ring in bacitracin $\mathrm{F}$ may not be a good ligand for metal binding as the antibiotic bleomycin has two thiazole rings (a bithiazole group) that do not bind divalent metals (24a). In addition, the electronwithdrawing carbonyl group can also reduce the Lewis basicity of this ring, and reduces its $\mathrm{Co}$ (II) binding ability. An interaction between Ile- $1 \mathrm{NH}_{3}{ }^{+}$and Glu- $4 \mathrm{CO}_{2}{ }^{-}$or the Asn-12 backbone carbonyl, that may stabilize metal binding as discussed above, is also not possible.

Only two hyperfine-shifted signals could be seen at 68 and 52 ppm in $\mathrm{Co}(\mathrm{II})$-bacitracin $\mathrm{F}$ at pH 7.5 (Figure 8C), which can be clearly assigned to the His- $10 \mathrm{C}_{\delta} \mathrm{H}$ and $\mathrm{C}_{\epsilon} \mathrm{H}$ protons (cf. Figures 2 and 4). This indicates that only the His-10 imidazole ring of bacitracin $\mathrm{F}$ is able to bind to divalent transition metal ions under physiological conditions. Since the His imidazole ring is a potential metal binding ligand, this binding mode in bacitracin $\mathrm{F}$ is thus considered not specific.

Bactoprenyl pyrophosphate binds tightly to bacitracin $\mathrm{A}_{1}$ only in the presence of divalent metal ions such as $\mathrm{Zn}$ (II), whereas it does not bind to bacitracin $\mathrm{F}$ in the absence or presence of divalent metal ions (13). Based on our studies, the low antibiotic activity and the lack of lipid-pyrophosphate binding capability of bacitracin F must be attributable to its inappropriate binding of divalent metal ions.

\section{An NMR-Generated Structure of the Co(II)-Bacitracin $A_{1}$ Complex in Water}

A structural model of $\mathrm{Co}(\mathrm{II})$-bacitracin $\mathrm{A}_{1}$ in water was built on the Cerius ${ }^{2}$ molecular modeling program using the proton- $\mathrm{Co}$ (II) distances obtained from $T_{1}$ values as restraints (Figure 9A, Table 1). The structure indicates that the "tail" of the bacitracin peptide (Ile-1 to Glu-4) wraps around the $\mathrm{Co}$ (II) ion with only the imidazole ring of His-10 bridging the metal ion to the cyclic heptapeptide moiety. As shown in the structure, the His-10 imidazole, the Glu-4 carboxylate, and the thiazoline ring nitrogen could all be easily brought 

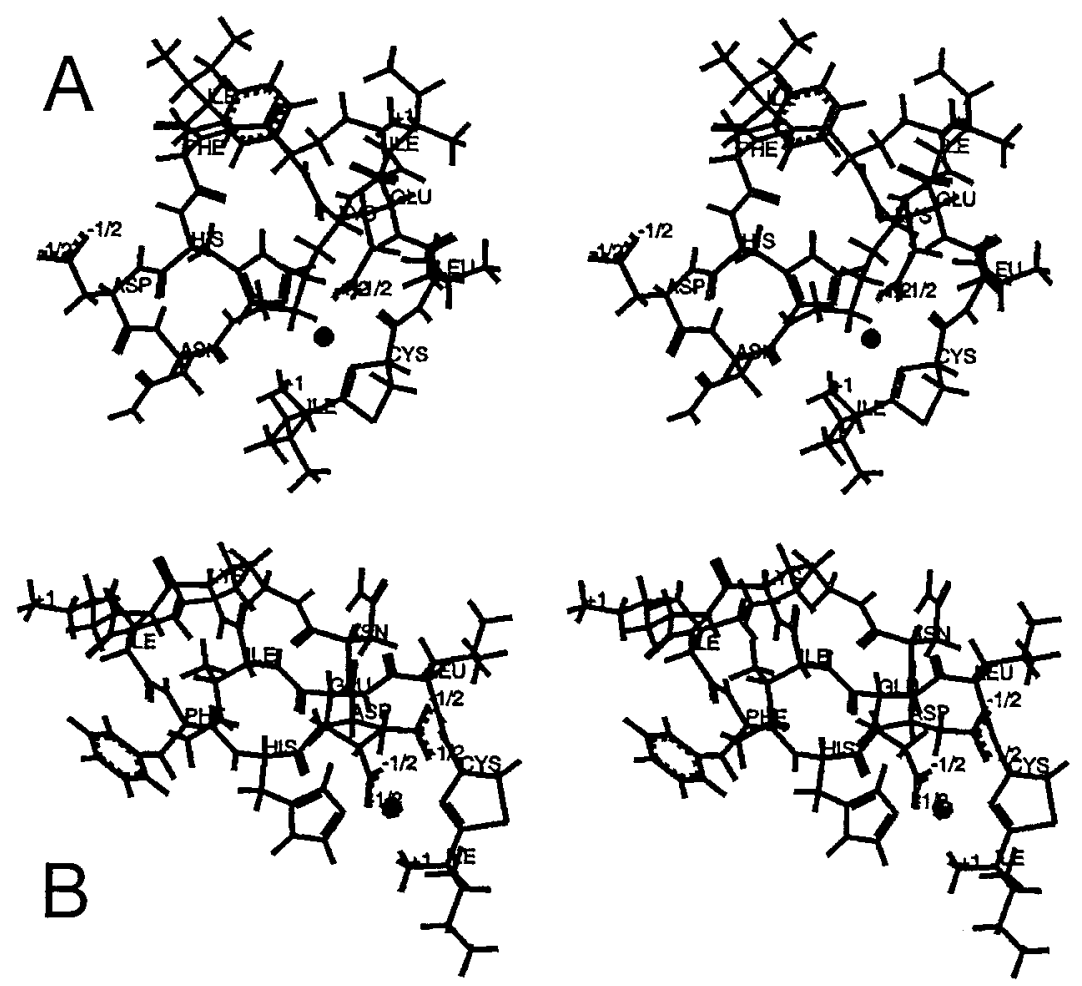

FIgURE 9: (A) Stereoview of Co(II)-bacitracin $\mathrm{A}_{1}$ structure produced by the use of the Cerius ${ }^{2}$ molecular modeling program. Distance constraints were obtained from the $T_{1}$ values of the assigned isotropically shifted ${ }^{1} \mathrm{H}$ NMR signals of the complex in $\mathrm{H}_{2} \mathrm{O}$ at $\mathrm{pH}$ 5.5. The structural model indicates that the N-terminus (Ile-1 to Glu-4) of bacitracin wraps around the $\mathrm{Co}$ (II) ion with only the His-10 imidazole ring bridging the cyclic heptapeptide to the $\mathrm{Co}$ (II) ion. The Phe-9 and the Ile-5 side chains are in close proximity and may serve as a flexible hydrophobic binding site for lipid pyrophosphates. Another low-energy conformer of the $\mathrm{Co}(\mathrm{II})$-bacitracin $\mathrm{A}_{1}$ complex with a $\mathrm{H}-$ bond between the unbound Glu-4 $\mathrm{O} \epsilon$ and Ile- $1 \mathrm{NH}_{3}{ }^{+}$is also shown (B). The model is rotated to clearly show this interaction. The overall structures of these two conformers are very similar, and are expected to be also similar to those of the Co(II) complexes of bacitracins $\mathrm{B}_{1}$ and $\mathrm{B}_{2}$ of high antibiotic potency. The $-\mathrm{NH}_{3}{ }^{+}$group of D-allo-Ile-1 in $\mathrm{Co}$ (II)-bacitracin $\mathrm{A}_{2}$ of low potency is expected to point to the opposite direction as that in Co(II)-bacitracin $\mathrm{A}_{1}$. The ligands from the drug in $\mathrm{Co}(\mathrm{II})$-bacitracin $\mathrm{A}_{2}$ are the His-10 imidazole and the thiazoline nitrogen, whereas Glu-4 is detached from the metal.

together to bind $\mathrm{Co}(\mathrm{II})$. Furthermore, the side chains of Phe-9 and Ile-5 are close to each other and may form a flexible hydrophobic pocket for the binding of the hydrocarbon chain of isoprenyl pyrophosphates. The wide-open Co(II) coordination sphere based on this model suggests that the geometry of the metal coordination may not be tetrahedral as indicated in the recent EXAFS study (12). The presence of a significant dipolar shift in the ${ }^{1} \mathrm{H}$ NMR spectrum and the observation of very weak $\mathrm{d}-\mathrm{d}$ transitions (spectrum not shown) in the Co(II) complexes of bacitracins are not consistent with such geometry, but rather a distorted 5- or 6-coordination sphere in solution under the experimental conditions in our studies. It is also interesting to note that the structure is quite different from that of the metal-free bacitracin determined previously by the use of NMR $(22 b)$ in which the side chains of Phe-9/Ile-8 were found to be close to Leu-3. This result further suggests that it is important to study the metal-bound form of metal-dependent biomolecules because of the potential structural difference with and without the bound metal.

The N-terminal amino group is not bound to the $\mathrm{Co}(\mathrm{II})$ at $<\mathrm{pH} 5.8$, but may form a hydrogen bond with the carbonyl oxygen of the Asn-12 backbone. An energetically comparable structure can also be built that places Ile- $1 \mathrm{NH}_{3}{ }^{+}$close enough to the free $\mathrm{O}_{\epsilon}$ of the monodentate Glu- $4 \mathrm{CO}_{2}{ }^{-}$to form a hydrogen bond (Figure 9B). Furthermore, this positively charged $-\mathrm{NH}_{3}{ }^{+}$is close to the $\mathrm{Co}$ (II) ion and could form a H-bond/charged interaction with the pyrophosphate moiety upon binding to the lipid pyrophosphates. This interaction may still be retained under physiological conditions since its interaction with a negatively charged group may prevent its deprotonation at neutral $\mathrm{pH}$.

Metal complexes of bacitracin $\mathrm{A}_{2}$ may not be able to form a H-bond between Ile-1 $\mathrm{NH}_{3}{ }^{+}$and the Asn-12 backbone carbonyl or Glu-4 $\mathrm{O}_{\epsilon}$ as in the case of $\mathrm{Co}(\mathrm{II})$-bacitracin $\mathrm{A}_{1}$. Bacitracin $\mathrm{A}_{2}$ has a D-allo-Ile-1 with the $-\mathrm{NH}_{3}{ }^{+}$group pointing away from the cyclic heptapeptide and the $\mathrm{Co}$ (II) ion as compared with the structure of $\mathrm{Co}$ (II)-bacitracin $\mathrm{A}_{1}$ (Figure 9). Moreover, this stereochemistry may also impede the interaction of Ile- $1 \mathrm{NH}_{3}{ }^{+}$with the pyrophosphate moiety of lipid pyrophosphates. These variations in the structure based on our NMR studies may explain the low biological activity of bacitracin $\mathrm{A}_{2}$.

\section{CONCLUSION}

The NMR studies presented here reveal that bacitracin binds to $\mathrm{Co}$ (II) ion via the $\mathrm{N}_{\epsilon}$ of the His-10 imidazole ring, the Glu-4 carboxylate, and the thiazoline ring nitrogen atom. The N-terminal amino group does not bind to the metal at $\mathrm{pH} \sim 5$, and there is no evidence in our study to support the binding of the Asp-11 carboxylate as suggested in a previous study (10b). The Co(II) complexes of several bacitracin analogues have also been examined, including bacitracins $A_{2}, B_{1}, B_{2}$, and $F$. Bacitracins $B_{1}$ and $B_{2}$ are known to show only a modest decrease in biological activity compared to 
the "high potency" bacitracin $\mathrm{A}_{1}$ and display similar isotropically shifted ${ }^{1} \mathrm{H}$ NMR features to bacitracin $A_{1}$ upon $\mathrm{Co}$ (II) binding. These results indicate a similar metal binding environment and overall structure of these analogues. On the other hand, those with negligible or highly reduced biological activities, including bacitracins $\mathrm{F}$ and $\mathrm{A}_{2}$, have very different metal binding modes from bacitracin $A_{1}$ on the basis of their isotropically shifted ${ }^{1} \mathrm{H}$ NMR features, reflecting different structures of the metal binding site from that of bacitracin $A_{1}$.

Even though bacitracin $\mathrm{F}$ can bind $\mathrm{Co}(\mathrm{II})$ at $\mathrm{pH} 7$, it does not have a metal binding site that can bind to lipid pyrophosphates such as bacitracin $\mathrm{A}_{1}$. Bacitracin $\mathrm{A}_{2}$ is also found to have a different $\mathrm{Co}$ (II) binding mode from bacitracin $\mathrm{A}_{1}$, indicating that the inversion at only one asymmetric center of an amino acid not directly involved in metal binding (i.e., from L-Ile-1 to D-allo-Ile-1) can result in a change of the metal binding site which might bring about a dramatic decrease in the biological activity of bacitracin. It is worth noting that the detachment of ligands from the "low potency" $\mathrm{Co}$ (II)-bacitracin analogues can be unambiguously concluded based on the disappearance of the isotropically shifted signals, which cannot be clearly revealed in a diamagnetic counterpart such as $\mathrm{Zn}(\mathrm{II})$-bacitracin. The relationship between the biological activity of bacitracin and its metal binding and its structure has been established in the studies presented here. Future studies on the binding of pyrophosphate and its lipid derivatives with $\mathrm{Co}$ (II) complexes of bacitracin analogues by means of NMR techniques should provide more information about the mechanism of the action of bacitracin at the molecular levels.

\section{ACKNOWLEDGMENT}

We are grateful to Dr. George Newkome for the use of his DRX250 NMR spectrometer, Isco model 2340 HPLC, and Cerius ${ }^{2}$ molecular modeling program. The Bruker ESQUIRE-electrospray ion-trap mass spectrometer was purchased with funds provided by the National Science Foundation (Grant BIR951208) and the University of South Florida.

\section{SUPPORTING INFORMATION AVAILABLE}

Two figures showing the spectra for assignments of Leu-3 and Glu-4 (3 pages). This material is available free of charge via the Internet at http://pubs.acs.org.

\section{REFERENCES}

1. Silverman, R. B. (1992) The Organic Chemistry of Drug Design and Drug Action, Academic Press, San Diego, CA.

2. Northey, E. H. (1948) American Chemical Society Monograph Series, Reinhold, New York.

3. Wei, X., and Ming, L.-J. (1998) J. Chem. Soc., Dalton Trans., 2793-2798.

4. Brewer, G. A., and Florey, K., Eds. (1980) Anal. Profiles Drug Subst. 9, 1-69.

5. (a) Hanson, D. J. (1985) Chem. Eng. News 63, 711. (b) Yagasaki, T. (1986) Food Hyg. Soc. Jpn. 27, 451.

6. Arky, R. (1997) Physicians' Desk Reference for Nonprescription Drugs, 18th Ed., Medical Economics Co., Montvale, NJ.

7. (a) Morris, M. (1994) Biol. Mass Spectrosc. 23, 61-70. (b) Siegel, M. M., Huang, J., Lin, B., and Tsao, R. (1994) Biol. Mass Spectrosc. 23, 196-204.
8. Pfeffer, S., Hohne, W., Branner, S., Wilson, K., and Betzel, C. (1991) FEBS Lett. 285, 115-119.

9. Storm, D. R., and Strominger, J. L. (1974) J. Biol. Chem. 249, 1823-1827.

10. (a) Scogin, D. A., Mosberg, H. I., Storm, D. R., and Gennis, R. B. (1980) Biochemistry 19, 3348-3342. (b) Seebauer, E. G., Duliba, E. P., Scogin, D. A., Gennis, R. B., and Belford, R. L. (1983) J. Am. Chem. Soc. 105, 4926-4929.

11. Mosberg, H. I., Scogin, D. A., Storm, D. R., and Gennis, R. B. (1980) Biochemistry 19, 3343-3347.

12. Drablos, F., Nicholson, D. G., and Ronning, M. (1999) Biochim. Biophys. Acta 1431, 433-442.

13. Storm, D. R., and Strominger, J. L. (1973) J. Biol. Chem. 248, 3940-3945.

14. Higashi, Y., Siewert, G., and Strominger, J. L. (1970) J. Biol. Chem. 245, 3683.

15. Stone, K. J., and Strominger, J. L. (1971) Proc. Natl. Acad. Sci. U.S.A. 68, 3223-3227.

16. (a) Bertini, I., and Luchinat, C. (1984) Adv. Inorg. Biochem. 6, 71-111. (b) Bertini, I., and Luchinat, C. (1986) NMR of Paramagnetic Molecules in Biological Systems, Benjamin/ Cummings, Menlo Park, CA. (c) Ming, L.-J. (2000) in Physical Methods in Bioinorganic Chemistry, Spectroscopy and Magnetism (Que, L., Jr., Ed.) University Science Books, CA.

17. Bertini I., and Luchinat C. (1994) in Bioinorganic Chemistry (Bertini, I., Gray, H. B., Lippard, S. J., and Valentine, J. S., Eds.) Chapter 2, University Science Books, CA.

18. )Ikai, Y., Oka, H., Hayakawa, J., Matusmoto, M., Saito, M., Harada, K., Mayumi, T., and Suzuki, M. (1995) J. Antibiot. 48, 233-242.

19. (a) Craig, L. C., and Konigsberg, W. (1957) J. Org. Chem. 22, 1345-1343. (b) Konigsberg, W., Hill, R. J., and Craig, L. C. (1961) J. Org. Chem. 26, 3867-3871. (c) Konigsberg, W., and Craig, L. C. (1962) J. Org. Chem. 27, 934-938.

20. Inubushi, T., and Becker, E. D. (1983) J. Magn. Reson. 51, $128-133$.

21. (a) Rappe, A. K., Casenit, C. J., Colwell, K. S., Goddard, W. A., III, and Skiff, W. M. (1992) J. Am. Chem. Soc. 114, 10024-10035. (b) Castonguay, L. A., and Rappe, A. K. (1992) J. Am. Chem. Soc. 114, 5832-5842.

22. (a) Pons, M., Feliz, M., Molins, M. A., and Giralt, E. (1991) Biopolymers 31, 605-612. (b) Kobayashi, N., Takenouchi, T., Endo, S., and Munekata, E. (1992) FEBS Lett. 305, 105109.

23. Weisiger, J. R., Hausmann, W., and Craig, L. C. (1955) J. Org. Chem. 77, 3123-3127.

24. (a) Lehmann, T. E., Ming, L.-J., Rosen, M. E., and Que, L. (1997) Biochemistry 36, 2807-2816. (b) Ming, L.-J., and Wei, X. (1994) Inorg. Chem. 33, 4617-4619. (c) Wei, X., and Ming, L.-J. (1998) Inorg. Chem. 37, 2253-2262.

25. La Mar, G. N., and de Ropp, J. S. (1993) in NMR of Paramagnetic Molecules (Berliner, L. J., and Reuben, J., Eds.) pp 1-73, Plenum Press, New York.

26. Bertini, I., Turano, P., and Vila, A. J. (1993) Chem. Rev. 93, 2833-2932.

27. Milner, R. S., and Pratt, L. (1962) Faraday Discuss. 34, 8895.

28. La Mar, G. N., Horrocks, W. DeW., Jr., and Holm, R. H. (1973) NMR of Paramagnetic Molecules, Principles and Applications, Academic Press, New York.

29. (a) Ming, L.-J., Lauffer, R. B., and Que, L., Jr. (1990) Inorg. Chem. 29, 3060-3064. (b) Salgado, J., Jimenez, H. R., and Moratal, J. M. (1996) Biochemistry 35, 1810-1819.

30. Scarrow, R. C., Pyrz, J. W., and Que, L., Jr. (1990) J. Am. Chem. Soc. 112, 657-665.

31. Konigsberg, W., and Craig, L. C. (1959) J. Am. Chem. Soc. $81,3452-3458$.

BI991997P 